\title{
PERSEPSI KONSUMEN TERHADAP SIRUP AIR KELAPA
}

Consumer Perception Of Coconut Water Syrup

\author{
Andi windi Indrawati ${ }^{1}$; Azhar Bafadal ${ }^{2}$; Sitti Aida Adha Taridala ${ }^{2}$ \\ ${ }^{1}$ Mahasiswa Program Studi Magister Agribisnis Universitas Halu Oleo \\ ${ }^{2}$ Program Studi Magister Agribisnis Universitas Halu Oleo \\ e-mail: awindra75@gmail.com
}

\begin{abstract}
Product syrup varies make consumers have different perceptions in choosing syrup products as they wish. Product attributes include marketing stimuli that can affect consumer perception. The purpose of this study was to determine the composition of coconut water taste syrup according to consumer perceptions. The design of this study is the experimental method and descriptive with the stage of product testing laboratory scale and descriptive analysis.

A test to determine the composition of flavors preference by consumers conducted by 25 panelists with two replications. Parameters measured were the taste, color, aroma and texture. The results show that the composition according to the taste of the consumer perception is coconut flavors syrup cocopandan water and adding sugar to $65 \%$ with an average value of 3.56. The average value of each attribute is a sense of 3.54, 3.72 color, aroma 3,58 and texture 3.56 .
\end{abstract}

Keywords: taste, coconut water syrup, Perception.

\begin{abstract}
ABSTRAK
Produk sirup yang bervariasi membuat konsumen memiliki persepsi yang berbeda-beda dalam memilih produk sirup sesuai keinginan mereka. Atribut produk termasuk stimuli pemasaran yang dapat mempengaruhi persepsi konsumen. Tujuan penelitian ini adalah mengetahui komposisi cita rasa sirup air kelapa sesuai dengan persepsi konsumen. Rancangan penelitian ini adalah Metode eksperimen dan deskriftif dengan tahapan uji coba produk skala laboratorium dan analisa deskriftif.

Uji kesukaan untuk mengetahui komposisi cita rasa yang disukai oleh konsumen dilakukan oleh 25 orang panelis dengan dua kali ulangan. Parameter yang diamati adalah rasa, warna, aroma dan tekstur. Hasil penelitian menunjukkan bahwa komposisi citarasa yang sesuai dengan persepsi konsumen adalah sirup air kelapa rasa cocopandan dan penambahan gula $65 \%$ dengan nilai rata-rata 3,56. Nilai rata-rata masing-masing atribut adalah rasa 3,54, warna 3,72, aroma 3,58 dan tekstur 3,56.
\end{abstract}

Kata Kunci : Cita rasa, Sirup air kelapa, Persepsi. 


\section{PENDAHULUAN}

Salah satu upaya pemanfaatan limbah air kelapa adalah dengan mengolahnya menjadi produk pangan yaitu sirup air kelapa. Sirup air kelapa berpotensi menjadi produk yang digemari masyarakat luas karena masih jarang ditemui. Sirup air kelapa dapat merupakan suatu usaha pengembangan produk dan dapat menunjang peningkatan nilai tambah dari komoditi kelapa.

Saat ini banyak produk sirup yang bermunculan dan menawarkan berbagai rasa yang beragam. Produk sirup yang bervariasi membuat konsumen memiliki persepsi yang berbeda dalam memilih produk sirup sesuai keinginan mereka. Persepsi sendiri merupakan salah satu faktor utama untuk mempengaruhi perilaku dan pilihan konsumen terhadap produk.

Produk sirup air kelapa ini masih tergolong baru dan belum banyak dikenal masyarakat umum khususnya di Kabupaten Konawe maka diperlukan penilaian mengenai persepsi konsumen terhadap sirup air kelapa.

Konsumen cenderung menyukai dan memilih produk sirup dengan inovasi yang baru yakni variasi rasa, warna, aroma dan tekstur yang sesuai selera. Hal tersebut merupakan atribut-atribut produk yang terdapat pada sirup air kelapa yang mempengaruhi konsumen. Pada dasarnya, atribut produk termasuk stimuli pemasaran yang dapat mempengaruhi persepsi konsumen. Persepsi konsumen terhadap produk sirup air kelapa tidak terlepas dari penilaian mereka terhadap atribut yang dibawa oleh sirup air kelapa yaitu rasa, aroma, warna dan tekstur.

Selain itu, produk sirup yang disukai oleh konsumen terletak pada cita rasanya. Citarasa merupakan gabungan dari penampilan dan rasa makanan/minuman. Kedua aspek ini sama pentingnya untuk diperhatikan agar dapat menghasilkan makanan/minuman yang dapat memuaskan konsumen (Moehyi, 1992). Salah satu cara untuk mengetahui komposisi cita rasa yang sesuai dengan harapan konsumen maka perlu dilakukan penilaian tingkat kesukaan panelis terhadap cita rasa sirup air kelapa yang ditawarkan. Penilaian terhadap suatu produk tergantung persepsi yang ada pada diri individu tersebut (Solomon, 1996).

Dengan adanya penilaian kesukaan panelis maka akan memberikan suatu gambaran cita rasa sirup air kelapa yang diterima dan diharapkan sesuai dengan persepsi konsumen. Tujuan dalam penelitian ini adalah untuk mengetahui komposisi cita rasa yang disukai konsumen dan persepsi konsumen terhadap sirup air kelapa.

\section{METODE PENELITIAN}

Rancangan penelitian yang digunakan untuk menjawab tujuan dalam penelitian ini adalah metode eksperimen dengan melakukan 
uji coba produk pembuatan sirup air kelapa pada skala laboratorium dengan perbedaan perlakuan yaitu sirup air kelapa dengan penambahan gula $85 \%$, $75 \%$ dan $65 \%$ dengan perbedaan rasa yaitu cocopandan dan pisang ambon.

\section{Lokasi Penelitian}

Uji coba produk dilaksanakan di laboratorium teknologi pasca panen SMK-PP Negeri Wawotobi Kab. Konawe.

\section{Sampel}

Sampel penelitian ini adalah panelis tidak terlatih sebanyak 25 orang. Metode pengambilan sampel panelis adalah dengan cara purposive sampling.

\section{Teknik Analisa Data}

Metode analisis yang digunakan untuk menjawab tujuan penelitian ini adalah dengan menggunakan analisis deskriftif untuk memberi gambaran terhadap persepsi cita rasa yang diperoleh dari nilai rata-rata tertinggi dari seluruh panelis yang menilai pada score sheet.

\section{HASIL DAN PEMBAHASAN}

Uji kesukaan untuk mengetahui komposisi cita rasa yang disukai oleh konsumen dilakukan oleh 25 orang panelis dengan dua kali ulangan. Parameter yang diamati adalah rasa, aroma, warna dan tekstur. Penilaian hasil pengujian terhadap seluruh produk sirup air kelapa pada setiap perbedaan perlakuan komposisi disajikan pada Tabel 1.

Tabel 1. Hasil Uji Kesukaan Panelis terhadap Sirup Air Kelapa

\begin{tabular}{|c|l|c|c|c|c|c|}
\hline \multirow{2}{*}{ No } & \multirow{2}{*}{$\begin{array}{l}\text { Kode Produk } \\
\text { dan Komposisi }\end{array}$} & \multicolumn{5}{|c|}{ Penilaian Sirup Air Kelapa } \\
\cline { 2 - 6 } 1 & $\begin{array}{l}\text { CAE 14 } \\
\text { Gula 85\% } \\
\text { Cocopandan }\end{array}$ & 3,50 & 3,48 & 3,50 & 3,52 & 3,50 \\
\hline 2 & $\begin{array}{l}\text { CAF 15 } \\
\text { Gula 75\% } \\
\text { Cocopandan }\end{array}$ & 3,64 & 3,39 & 3,56 & 3,42 & 3,50 \\
\hline 3 & $\begin{array}{l}\text { CAG 16 } \\
\text { Gula 65\% } \\
\text { Cocopandan }\end{array}$ & 3,72 & 3,54 & 3,58 & 3,40 & 3,56 \\
\hline 4 & $\begin{array}{l}\text { PAB 11 } \\
\text { Gula 85\% } \\
\text { Pisang Ambon }\end{array}$ & 3,40 & 2,74 & 3,14 & 3,54 & 3,22 \\
\hline 5 & $\begin{array}{l}\text { PAC 12 } \\
\text { Gula 75\% } \\
\text { Pisang Ambon }\end{array}$ & 3,40 & 2,98 & 3,10 & 3,46 & 3,23 \\
\hline 6 & $\begin{array}{l}\text { PAD 13 } \\
\text { Gula 65\% } \\
\text { Pisang Ambon }\end{array}$ & 3,16 & 2,76 & 3,16 & 3,44 & 3,13 \\
\hline
\end{tabular}

Penilaian panelis terhadap masingmasing parameter dibahas satu persatu berdasarkan nilai rata-rata.

\section{Warna}

Warna merupakan salah satu penentu mutu makanan yang penting, terutama dalam pemasaran produk pangan. Sebelum faktor mutu lainnya dipertimbangkan seperti rasa, aroma, dan tekstur secara visual faktor warna tampil terlebih dahulu (Satuhu, 2004).

Gambar 1 menunjukkan bahwa hasil pengujian terhadap warna sirup air kelapa panelis memberikan nilai tertinggi pada sirup dengan komposisi gula $65 \%$ dan rasa cocopandan dengan skor 3,72. Hal ini 
disebabkan warna sirup yang terlihat menarik. Umumnya warna dalam suatu makanan dipengaruhi oleh formula bahan baku. Selain itu, proses pengolahan juga mempengaruhi warna produk yang dihasilkan (Winarno, 2008).

Nilai terendah diberikan panelis pada sirup air kelapa dengan komposisi gula $65 \%$ dan rasa pisang ambon yang mempunyai warna terlalu merah dengan skor 3,14.

Gambar 1. Nilai Kesukaan Warna

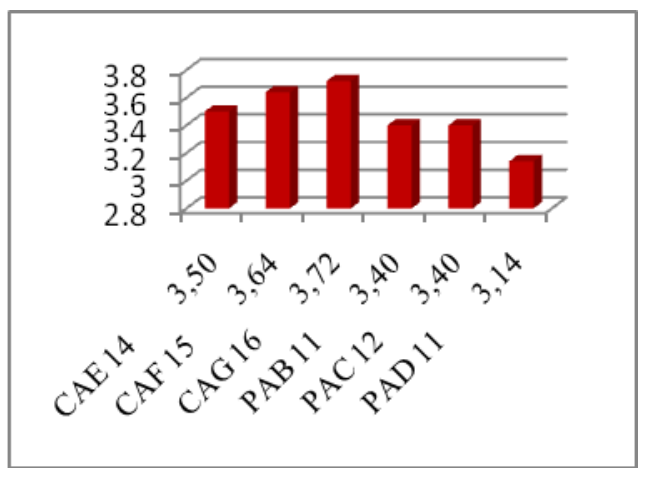

\section{Rasa}

Tingkat kemanisan merupakan faktor yang mempengaruhi cita rasa suatu produk pangan. Fungsi sukrosa disamping sebagai pemanis juga berfungsi dapat meningkatkan penerimaan satu jenis makanan karena dapat menutupi cita rasa yang tidak menyenangkan dari makanan tersebut (Satuhu, 2004).

Gambar 2 menunjukkan panelis memberikan nilai tertinggi pada sirup air kelapa dengan komposisi penambahan gula $65 \%$ dengan rasa cocopandan. Sirup ini mempunyai rasa manis yang bercampur dengan rasa manis dari air kelapa sehingga menimbulkan sensasi rasa segar dengan nilai 3,54 . Konsentrasi gula yang digunakan pada pembuatan sirup selain bersifat memberi rasa manis juga mempengaruhi flavor yang ideal (Luthony, 1993). Nilai terendah diberikan panelis pada sirup dengan komposisi $85 \%$ dan rasa pisang ambon dengan skor 2,74.

Gambar 2. Nilai Kesukaan Rasa

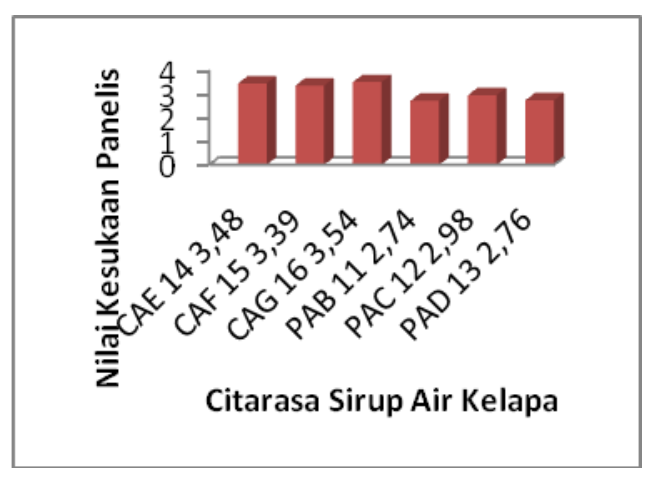

\section{Aroma}

Pengujian terhadap aroma dianggap penting karena cepat memberikan penilaian diterima/ tidaknya produk tersebut.

Pada Gambar 3 terlihat panelis memberikan nilai tertinggi pada sirup air kelapa dengan komposisi gula $65 \%$ dan rasa cocopandan dengan nilai 3,58.

Nilai terendah diberikan panelis dengan komposisi gula $75 \%$ dan rasa pisang ambon dengan skor 3,10. Aroma sirup pada umumnya tergantung dari bahan yang digunakan dan aroma dapat ditimbulkan dari aroma air kelapa, essens yang ditambahkan serta aroma gula.

Nilai terendah diberikan panelis dengan komposisi gula $75 \%$ dan rasa pisang ambon 
dengan skor 3,10. Aroma sirup pada umumnya tergantung dari bahan yang digunakan dan aroma dapat ditimbulkan dari aroma air kelapa, essens yang ditambahkan serta aroma gula.

Gambar 3. Nilai Kesukaan Aroma

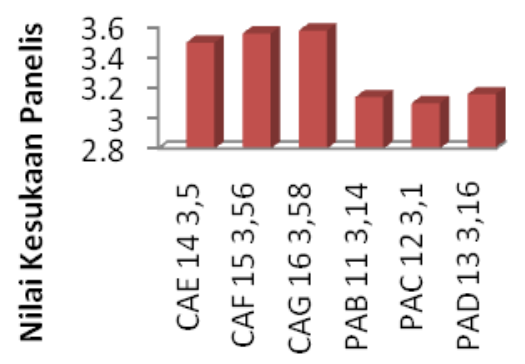

Citarasa Sirup Air Kelapa

\section{Tekstur}

Kekentalan sirup merupakan salah satu faktor mutu secara fisik yang mempengaruhi kesukaan panelis untuk menyukai produk sirup. Pada Gambar 4 terlihat penilaian panelis tertinggi diberikan pada sirup air kelapa dengan komposisi gula $85 \%$ dan rasa pisang ambon dengan skor 3,54.

Nilai terendah diberikan pada sirup air kelapa dengan konsentrasi gula $75 \%$. Kekentalan sirup dipengaruhi oleh konsentrasi gula dan lama pemanasan, semakin besar jumlah gula yang diberikan maka kekentalan sirup semakin meningkat. Lama pemanasan juga mempengaruhi kekentalan dari sirup, semakin lama waktu pemanasan kekentalan semakin meningkat karena degradasi gula.
Gambar 4. Nilai Kesukaan Tekstur

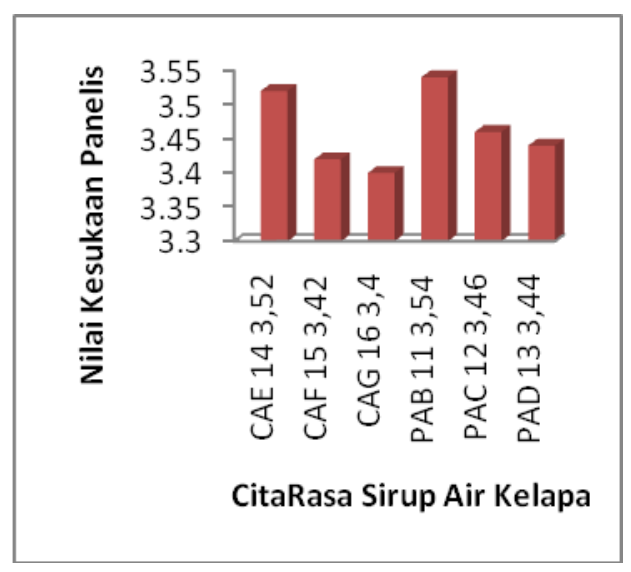

\section{Persepsi Konsumen}

Persepsi adalah proses dimana sensasi yang diterima oleh seseorang dipilah dan dipilih, kemudian diatur dan akhirnya diinterprestasikan. Sensasi datang dan diterima oleh manusia melalui panca indra, yaitu mata, hidung, mulut, telinga dan kulit yang disebut dengan sistem sensorik.

Uji kesukaan yang dilakukan oleh panelis dalam penelitian ini bertujuan untuk mengetahui persepsi konsumen terhadap citarasa sirup air kelapa melalui uji sensorik terhadap rasa, warna,aroma dan tekstur. Citarasa makanan merupakan salah satu faktor yang mempengaruhi daya terima terhadap makanan yang disajikan. Menurut Soegeng (2004), citarasa makanan menimbulkan terjadinya rangsangan terhadap berbagai indera dalam tubuh manusia, 
terutama indera penglihatan, penciuman dan indera pengecap. Persepsi setiap orang terhadap suatu objek akan berbeda-beda, karena itu persepsi mempunyai sifat yang subjektif. Faktor-faktor yang mempengaruhi persepsi seseorang atas makanan adalah demografi (suku, budaya, usia, pendidikan), lingkungan, dan mutu makanan (Prasetijo, 2004).

Panelis dalam penelitian ini berjumlah 25 orang yang berasal dari suku yang berbeda dan usia serta pendidikan yang berbeda. Suku usia, dan pendidikan panelis merupakan karakteristik yang berpengaruh pada persepsi konsumen terhadap citarasa sirup air kelapa. Panelis pada penelitian ini lebih menyukai rasa, warna dan aroma sirup air kelapa dengan penambahan gula $65 \%$ dibandingkan dengan penambahan gula $75 \%$ dan $85 \%$ atau dapat dikatakan panelis lebih menyukai sirup air kelapa dengan tingkat kemanisan yang rendah (Gambar 5).

Hal ini dikarenakan rasa manis yang berlebihan pada umumnya menyebabkan rasa eneg pada sebagian besar panelis dan menyebabkan sirup air kelapa pada tingkat kemanisan yang tinggi tidak disukai oleh panelis.

Gambar 5. Nilai Rata-rata Kesukaan Panelis

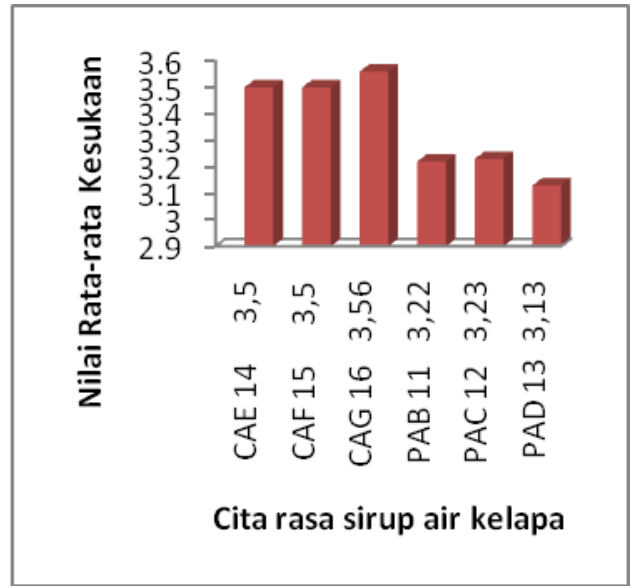

Citarasa suatu makanan sesuai dengan selera daerah. Umumnya daerah Sulawesi dengan berbagai sukunya dan daerah jawa cenderung menyukai rasa yang manis. Faktor usia dan pendidikan dari panelis juga mempengaruhi penilaian panelis terhadap rasa sirup air kelapa. Panelis yang berpendidikan tinggi dan berusia dewasa cenderung memilih makanan melihat dari segi kesehatan. Tingkat kemanisan yang tinggi akan memberikan asumsi negatif dan dapat mengganggu kesehatan. Walaupun pada dasarnya produk sirup mempunyai tingkat kemanisan yang tinggi karena penggunaan gula yang cukup banyak, namun respons masing-masing panelis berbeda. Tanggapan yang berbeda terhadap rasa ini merupakan hal yang perlu diperhatikan agar konsumen mempunyai persepsi yang baik terhadap produk.

Persepsi warna dapat mempengaruhi rasa, ketika konsumen melihat warna yang menarik maka makanan itu pasti terasa enak menurut persepsi mereka. Warna mempunyai 
konotasi inderawi yang penting. Warna pada produk makanan akan memberikan sensasi dari indera penglihatan dan akhirnya mempengaruhi persepsi konsumen terhadap produk tersebut. Warna dari sirup air kelapa berasal dari penambahan essens cocopandan yang berwarna merah. Dalam psikologi, warna merah berarti energi, kekuatan dan kegembiraan, sehingga warna merah dapat merangsang indra fisik dan meransang nafsu makan (Hardiyanto, 2012). Panelis menyukai sirup air kelapa dengan penambahan gula $65 \%$ dan rasa cocopandan karena sirup ini memiliki warna merah yang tidak terlalu mencolok dibanding dengan sirup yang diberi perlakuan berbeda. Pengaruh usia dan budaya juga mempengaruhi persepsi panelis terhadap warna. Dalam budaya timur warna merah dianggap sebagai warna keberuntungan.

Aroma sirup pada umumnya tergantung dari bahan yang digunakan dan aroma dapat ditimbulkan dari aroma khas air kelapa, essens yang ditambahkan serta aroma gula. Aroma merupakan salah satu komponen cita rasa pada makanan, yaitu memberikan aroma atau bau, maka dapat mengetahui rasa dari makanan tersebut. Dimana aroma ini dikenal dengan menggunakan hidung. Panelis menyukai sirup air kelapa dengan aroma cocopandan. Hal ini dikarenakan aroma cocopandan yang berpadu dengan aroma dari air kelapa menghasilkan aroma yang khas.
Faktor pribadi dan pengalaman masa lalu panelis sangat berpengaruh terhadap kesukaan pada aroma sirup air kelapa.

Tekstur dan konsistensi suatu bahan akan mempengaruhi cita rasa yang ditimbulkan oleh bahan tersebut.Tekstur atau kekentalan yang disukai oleh panelis adalah tekstur sirup air kelapa dengan perlakuan gula $85 \%$ dan rasa pisang ambon. Tekstur sirup air kelapa ini cenderung lebih kental. Kekentalan sirup merupakan salah satu faktor mutu secara fisik yang mempengaruhi kesukaan panelis. Selain faktor fisik, pengalaman panelis dalam membeli sirup dan pengetahuan panelis tentang sirup juga sangat mempengaruhi kesukaan panelis.

Dari hasil penilaian panelis terhadap atribut sirup air kelapa melalui uji sensoris bahwa konsumen memiliki persepsi yang baik terhadap atribut-atribut sirup air kelapa. Sensoris merespon pada rasa, aroma, warna dan tekstur membantu untuk menentukan preferensi konsumen terhadap citarasa sirup air kelapa. Persepsi yang sudah mengendap dan melekat dalam pikiran akan menjadi preferensi (Assael, 1984).

\section{KESIMPULAN DAN SARAN}

\section{Kesimpulan}

Konsumen secara umum melalui uji kesukaan panelis memiliki persepsi yang baik terhadap sirup air kelapa. 
Komposisi citarasa yang disukai yang sesuai dengan pesepsi konsumen adalah sirup air kelapa dengan rasa cocopandan dan penambahan gula $65 \%$.

\section{Saran}

Berdasarkan penelitian yang telah
dilakukan disarankan untuk peneliti
selanjutnya untuk melakukan penambahan
atribut lain seperti harga dan kemasan. Selain
itu perlu lebih ditekankan pada karakteristik
suku dan budaya konsumen.

\section{Daftar Pustaka}

Assael, H. 1992. Consumer Behavior and Marketing Action. Kent Publising. Boston.

Assegaf, M. dan Yusuf. 2004. Prospek Pengembangan Usaha Agroindustri Skala Rumahtangga Sirup Air Kelapa dalam Kemasan Botol dan Gelas Plastik. http://ntb.litbang.deptan.go.id

Hardiyanto, D., Usman Effendi dan Ika Atsari Dewi. 2012. Preferensi Konsumen terhadap Produk Selai Buah Nipah Menggunakan Analisis Konjoin. Jurnal Teknologi Industri Pertanian. Universitas Brawijaya.

Luthony, TL. 1993. Tanaman Sumber Pemanis. Swadaya. Jakarta.

Moehyi, S. 1992. Penyelenggaraan Makanan Institusi Jasa Boga. Bhatara. Jakarta.

Prasetijo, R. dan J. Ihalauw. 2005. Perilaku Konsumen untuk Bisnis. Andi. Yogyakarta.

Satuhu, S. 2003. Pengolahan Buah. Penebar Swadaya. Jakarta.
Soegeng, 2004. Kesehatan dan Gizi. PT. Bumi Aksara. Jakarta.

Winarno, F.G. 2014. Kelapa Pohon Kehidupan. Gramedia. Jakarta. 